\title{
Análise de Redes Sociais: a formação de grupos do Facebook frente à epidemia da COVID-19 no Brasil
}

\author{
Fabio Rocha de Paula*, Marcia Gomide da Silva Mello \\ Programa de Pós-Graduação em Saúde Coletiva da Universidade Federal do Rio de Janeiro (IESC/UFRJ), \\ Rio de Janeiro, RJ, Brasil
}

Histórico do Artigo

Recebido em:

11/05/2020

Aceito em:

04/06/2020.

Palavras-chave:

Análise de Redes

Sociais; Facebook;

coronavírus;

COVID-19

Keywords:

Social Network

Analysis; Facebook;

coronavirus;

COVID-19

\begin{abstract}
RESUMO
Diversas epidemias ao longo da história já trouxeram mortes e agravos à saúde da humanidade e, mais recentemente o mundo experimenta os efeitos de uma nova pandemia a COVID-19. Esta se diferencia de tantas outras pelo fato de estar ocorrendo em um período no qual a população mundial vivencia a era da tecnologia das mídias sociais em que a velocidade do fluxo de informação é instantânea. A mídia social Facebook possui milhares de usuários em sua plataforma que através de grupos compartilham diversos conteúdos relacionados ao coronavírus. Com o objetivo de aplicar a teoria da Análise de Redes Sociais (ARS), avaliou-se a possibilidade de utilização deste instrumental na compreensão da formação de grupos do Facebook no auxílio a possíveis políticas públicas em saúde nesse momento de epidemia no Brasil. Com caráter descritivo, foram pesquisados grupos no Facebook que apresentam características de postagens relacionadas ao coronavírus ou a COVID-19. Verificou-se que os assuntos informação, solidariedade e educação foram os que mais se evidenciaram entre a formação dos grupos pesquisados. Mesmo com a limitação de análise sugere-se que a utilização da ARS, mostra-se elemento de compreensão às necessidades da população a serem utilizadas como alicerces às políticas públicas em saúde no Brasil nesse momento, tendo as mídias sociais papel relevante num mundo cada vez mais conectado.
\end{abstract}

Social Network Analysis: the formation of Facebook groups in the face of the COVID-19 epidemic in Brazil

\section{ABSTRACT}

Several epidemics throughout history have already brought deaths and health problems to humanity and, more recently, the world is experiencing the effects of a new pandemic to COVID-19. This differs from so many others in that it is taking place at a time when the world population is experiencing the age of social media technology in which the speed of information flow is instantaneous. Facebook social media has thousands of users on its platform who, through groups, share several contents related to the coronavirus. In order to apply the theory of Social Network Analysis (SNA), the possibility of using this tool to understand the formation of Facebook groups to help possible public health policies at this time of epidemic in Brazil was evaluated. Descriptively, groups were searched on Facebook that have characteristics of posts related to the coronavirus or COVID-19. It was found that the subjects of information, solidarity and education were the most evident among the formation of the researched groups. Even with the limitation of analysis, it is suggested that the use of SNA is an element of understanding the needs of the population to be used as a foundation for public health policies in Brazil at that time, with social media playing a relevant role in an increasingly world more connected.

\section{Introdução}

A humanidade ao longo de sua história tem sofrido com grandes impactos causados por agentes patogênicos como vírus, bactérias e outros microrganismos que assolam o mundo desde os tempos mais remotos, de cujos registros evidenciam ocorrências epidêmicas há pelo menos 400 anos antes de Cristo (1), partindo do século VI com a conhecida "Praga de Justiniano", passando pelo século XIV com a "Peste Negra", prosseguindo pelo século

\footnotetext{
* Autor correspondente: fabiorocha2008@gmail.com (de Paula F.R.)
} 
XX com a "Gripe Espanhola", causando mortes e agravos a saúde até os dias atuais representadas pelas epidemias do século XXI, como a Síndrome Respiratória Aguda Grave em 2003, Influenza H1N1 em 2009, Ebola em 2014 e Zika Vírus em 2016 (2).

Epidemias, endemias e pandemias podem ocorrer por causas multifatoriais, dentre elas destacam-se a globalização das doenças, mutações de agentes patogênicos, condições sanitárias precárias como falta de saneamento básico, dificuldades no controle dos surtos, e até mesmo o desmatamento (3). Tendo em vista que diversas doenças que assolaram o mundo, romperam fronteiras políticas, sociais, étnicas e econômicas, em se tratando de pandemias as mais notáveis e com amplas repercussões espaço-temporais trouxeram fortes consequências no colapso demográfico (4), e mais recentemente em 2020, quando o mundo experimenta os efeitos de uma nova pandemia denominada COVID-19.

Essa pandemia tem origem em 29 de dezembro de 2019 quando quatro pessoas foram admitidas em um hospital de Wuhan uma província de Hubei, localizada na República Popular da China, essas pessoas que apresentavam um quadro grave de pneumonia, eram trabalhadores de um mercado atacadista de frutos do mar de Huanan, conhecido pelo comércio ao grande público de produtos aquáticos, aves vivas e várias espécies de animais selvagens (5). Assim foram coletadas amostras respiratórias desses pacientes e enviadas aos laboratórios de referência para investigações etiológicas, o hospital relatou essa ocorrência ao Centro de Controle de Doenças (CDC) da China e, os epidemiologistas de campo desse país (FETP-China) encontraram pacientes adicionais vinculados ao mercado e, em 30 de dezembro, as autoridades de saúde da província de Hubei notificaram esse cluster ao CDC da China que posteriormente, em 31 de dezembro notificou o surto à Organização Mundial de Saúde (6). A doença causada pelo agente etiológico novo coronavírus (SARS-CoV-2), recebeu a denominação COVID-19 em referência ao tipo de vírus e ao ano de início da epidemia: Coronavirus disease -2019 (7).

No Brasil, oficialmente o primeiro caso de COVID-19 foi confirmado em 26 de fevereiro de 2020. Em 3 de março, haviam 488 casos suspeitos notificados, 2 confirmados e 240 descartados no país, sem evidência de transmissão local. Os dois primeiros casos confirmados eram de indivíduos do sexo masculino, residentes na cidade de São Paulo, SP, que haviam regressado de viagem à Itália (8). Porém em 11 de março de $2020 \mathrm{a}$ Organização Mundial de Saúde (OMS) declarou oficialmente a COVID-19 como pandemia, com mais de 110 mil casos e 4 mil óbitos em países de todos os continentes (9), e no Brasil a epidemia declarada Emergência de Saúde Pública de Importância Nacional, nível este em que há confirmação de transmissão local entre indivíduos. Dessa forma, de acordo com dados mais recentes (03 de junho de 2020), do boletim epidemiológico do Ministério da Saúde, até o momento da elaboração da pesquisa, com estimativas sujeitas a revisão, o país apresenta 584.016 casos confirmados, $312.851 \mathrm{em}$ acompanhamento (53,6\%), 32.548 óbitos, 238.617 recuperados (40,8\%), com 5,6\% de letalidade (10).

Como tal pandemia é ocasionada por um agente etiológico o qual ainda se tem aprendido muito sobre seu mecanismo de ação bem como sua letalidade, não se tem muita clareza sobre seus aspectos clínicos e epidemiológicos, porém sabe-se que a letalidade da COVID-19 pode ser afetada por fatores como conhecimento sobre a doença, capacidade diagnóstica instalada e superlotação hospitalar (11). A capacidade de resposta dos países certamente depende da configuração de seus sistemas de saúde, mesmo na Itália, com um sistema universal de atenção à saúde considerado um dos melhores da Europa, a assistência hospitalar chega ao limite da sua capacidade de resposta aos pacientes que necessitam de internação e cuidados intensivos (12).

Além de afetar diretamente a saúde das pessoas que são infectadas, essa pandemia traz consigo diversas consequências que se desdobram em problemas nas áreas econômica, 
política e social, pois de alguma forma expõe as fragilidades desses setores, em alguns países com gravidades maiores que outros, pois que o enfrentamento à COVID-19 deve incorporar a realidade de países com ampla diversidade socioeconômica e carga de doença (13). Talvez a grande questão consista na maneira como a população mundial esteja aprendendo a lidar com essa doença, em meio a tantas informações que são veiculadas pelos meios de comunicação, seja pelas mídias tradicionais (rádio e televisão), ou através das plataformas digitais. Estas últimas, ganharam grande importância, uma vez que se tem acesso à informação em tempo real sobre números de casos de óbitos e de pessoas recuperadas, diante de recomendações adotadas pelos países quanto a prevenção, uso de álcool gel 70\% para assepsia das mãos, uso de máscaras e o distanciamento social: a denominada quarentena (14). Tais medidas por enquanto são plausíveis em face a ausência de imunidade prévia da população bem como de uma vacina contra o SARSCoV-2 (9). No entanto tais medidas restritivas adotadas por muitos países para conter o surto e sobrecarga no sistema de saúde, podem trazer, além das consequências sociais e econômicas, profundos efeitos a saúde física e mental da população, os quais precisarão ser avaliados futuramente (15). Porém diversos centros de pesquisa ao redor do mundo não têm medido esforços em busca de terapias capazes de combater os efeitos mais graves da doença e dessa forma a cloroquina, surge como uma dessas drogas capazes de inibir a replicação in vitro de vários tipos de coronavírus, podendo melhorar o resultado clínico de pacientes infectados pelo SARS-Cov-2, apesar da necessidade de aprofundamento desses resultados (16). O fato é que a pandemia surge em um período diferenciado da história, por ser essa a primeira da era tecnológica das mídias sociais.

Nesse contexto presencia-se a ascensão do desenvolvimento de tecnologias de comunicação e informação sobretudo dos sites de redes sociais digitais, com seu papel preponderante na sociedade atual, seja na difusão de informações e ou opiniões em relação aos mais diversos assuntos, ao passo que o jornalismo tradicional vem entrando em uma crise de confiança do grande público (17). Personalidades das áreas da política, entretenimento e anônimos têm usufruído das mídias sociais para se comunicarem com seus seguidores tanto no Brasil quanto ao redor do mundo. E de certo, tem alcançado seu intento, algumas das vezes de forma positiva ou negativa, haja vista que essas plataformas de redes sociais digitais têm se tornado um espaço primordial para a informação - e desinformação - na atualidade. Por exemplo, 57\% dos brasileiros que mantêm contas ativas no Facebook informam-se pela plataforma, de acordo com o relatório publicado em 2018 pela Digital News Report (18).

Dado o contexto das mídias sociais, o Facebook tem sido considerada uma plataforma de grande relevância ante o cenário de buscas e compartilhamento de conteúdo relacionado à saúde, principalmente devido à sua natureza interativa que facilita a troca de apoio social (19), com grande capacidade de influenciar o discurso público sobre saúde de maneira "viral", tanto positiva quanto negativamente (20), ganhando relevância ainda maior nesse período de isolamento social no qual muitos usuários se apropriam de tal ferramenta para comunicação. De fato, não se pode negar a força das mídias sociais na atualidade pela qual os usuários, em uma nova configuração, se comunicam e compartilham informações, cabendo, portanto, analisá-las pela perspectiva da Análise de Redes Sociais (ARS).

A ARS é uma teoria, de caráter multidisciplinar, tradicionalmente utilizada com o objetivo de estudar as redes sociais, sejam aquelas ditas "invisíveis" (21), espontâneas, informais e não intencionais oriundas das inter-relações em sociedade, ou aquelas de caráter formal, dentre outras, tais como: associações, organizações, clubes, cooperações, ou seja, permite analisar a estrutura das ligações existentes entre "nós" que compõem as redes sociais $(22,23)$. A ARS em si, pode ser utilizada como um instrumento indutivo da 
investigação social, que possuindo o propósito de identificar os tipos de relações existentes entre os atores, mede de forma sistemática os comportamentos relacionais desses atores (24). Diante disso a ARS pode ser usada como uma ferramenta analítica para investigação de fluxo de informações entre grupos do Facebook, sendo relevante pois entender as formas expressadas pelos usuários de tal plataforma com grande acesso global é entender, de certa forma, a demanda de um número expressivo de indivíduos, sendo útil inclusive no atendimento às necessidades de saúde da população em possíveis políticas públicas de comunicação em saúde. Portanto o presente artigo, pretende aplicar o instrumental teórico-metodológico pertinente a ARS como suporte avaliativo à compreensão quanto à formação de grupos do Facebook, referentes à pandemia da COVID-19 ocasionada pelo agente etiológico novo coronavírus.

\section{Materiais e métodos}

Este artigo de caráter descritivo, utilizou-se da teoria da ARS como suporte na compreensão da formação de grupos do Facebook no período de pandemia da COVID19 no Brasil. A coleta de dados realizou-se pela busca de grupos através da mídia social e ou rede social virtual Facebook, de acesso livre e gratuito, desde que o usuário se auto declare ter pelo menos 13 anos de idade. No site da mídia social, no menu superior buscou-se pelo item "grupos" e acima na aba "pesquisar" inseriu-se a palavra coronavírus, sem aspas, por ser uma palavra mais intuitiva, sem exigência de conhecimento específico, tal como um cidadão que busca informação para um problema que desperta o interesse como se o pesquisador fizesse parte deste grupo de internautas leigos (25). A sequência do critério de seleção, seguiram-se com as etapas: no item filtrar resultados, foi selecionado em publicações de: qualquer pessoa; tipo de publicação: todas as publicações; publicado no grupo: qualquer grupo; localização marcada: em qualquer lugar e em data de publicação: ano de 2020. Na aba superior no item grupos selecionouse em mostrar apenas: qualquer grupo, para que abrangessem tantos grupos públicos quanto privados, e no item membros selecionou-se qualquer grupo, de forma que pudessem ser encontrados grupos não apenas nos quais os pesquisadores participassem, evitando assim o viés de seleção (26).

A coleta de dados foi realizada no dia 15/04/2020, conforme se tem empregado em pesquisas que buscam informações virtuais (27). Foram encontrados 86 grupos dos quais 69 foram selecionados pelo critério de inclusão, cujo teor do conteúdo de postagens, assim como na descrição do grupo tivessem vinculação com o coronavírus e ou COVID-19, sem delimitação geográfica no Brasil. Como critério de exclusão, grupos que não tiveram conteúdo ou postagens relacionadas ao tema pesquisado, se desviando da proposta, foram retirados. Os grupos selecionados foram então categorizados de acordo com a descrição estabelecida e assim definidos por assuntos relacionados ao coronavírus, tanto em seu título, quanto em seu conteúdo, da seguinte maneira: educação, espiritualidade, humor, informação, política e solidariedade. Informações relacionadas ao número total de membros nos grupos e total de postagens no dia foram também agregadas pelos assuntos supracitados.

Os dados foram organizados em uma planilha Excel/Windows, como lista de adjacências (constituída por uma planilha Excel onde as relações a partir de cada nó são colocadas em linhas separadas por vírgulas, permitindo a identificação dos mesmos com os demais adjacentes), seguindo critérios já realizados em outro estudo de características metodológicas similares (28). Denomina-se nó aos atores que compõem a rede. Podem representar pessoas, instituições, serviços etc. (29). Nessa pesquisa, os assuntos relacionados ao coronavírus categorizados anteriormente, foram identificados como os 
nós. As relações dos nós seguem em cada linha, com os grupos do Facebook identificados conforme o assunto a eles pertinente. Os grupos foram então identificados como g1 até g69. O indicador de ocorrência de relação entre um grupo e um assunto, e vice-versa, demostra a configuração da relação existente entre ambos, bem como a maneira pela qual se dispõem na rede assim estabelecida na mídia social em torno do tema da pandemia COVID-19. A lista resultante foi salva em Excel no formato CSV e posteriormente aberta no software Gephi, de acesso livre, na versão 0.9.1, sob o algoritmo Fruchterman Reingold, produzindo os sociogramas para visualização e posteriores análises. Dentre as métricas possíveis a serem consideradas definiu-se a da centralidade como base de análise por corresponder mais adequadamente a proposta de visualização da amplitude das relações.

\section{Resultados}

O Quadro 1 apresenta os assuntos selecionados e categorizados de acordo com o descritor coronavírus, relacionados com os respectivos grupos do Facebook representados pelos códigos (g1 ao g69).

Quadro 1 - Assuntos relacionados ao coronavírus e os respectivos grupos do Facebook com suas características

\begin{tabular}{|c|c|c|c|c|}
\hline $\begin{array}{c}\text { ASSUNTOS } \\
\text { RELACIONADOS } \\
\text { AO } \\
\text { CORONAVÍRUS }\end{array}$ & $\begin{array}{c}\text { GRUPOS } \\
\text { DO FACEBOOK }\end{array}$ & $\begin{array}{c}\text { GRUPOS } \\
\text { ENCONTRADOS }\end{array}$ & $\begin{array}{c}\text { TOTAL DO } \\
\text { NÚMERO } \\
\text { DE } \\
\text { MEMBROS } \\
\text { NOS } \\
\text { GRUPOS }\end{array}$ & \begin{tabular}{|c} 
TOTAL DE \\
POSTAGENS \\
NO \\
DIA \\
POR ASSUNTO
\end{tabular} \\
\hline Educação & $\begin{array}{l}\mathrm{g} 7, \mathrm{~g} 15, \mathrm{~g} 19, \mathrm{~g} 20, \mathrm{~g} 21, \\
\mathrm{~g} 26, \mathrm{~g} 33, \mathrm{~g} 34, \mathrm{~g} 42, \\
\mathrm{~g} 45, \mathrm{~g} 58, \mathrm{~g} 61, \mathrm{~g} 62, \\
\mathrm{~g} 63, \mathrm{~g} 64\end{array}$ & 15 grupos & 84.676 & 1.370 \\
\hline Espiritualidade & $\mathrm{g} 10, \mathrm{~g} 54, \mathrm{~g} 57, \mathrm{~g} 60$ & 4 grupos & 10.981 & 1.080 \\
\hline Humor & 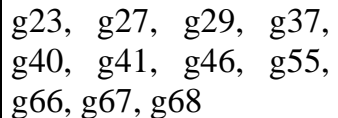 & 11 grupos & 1.385 .992 & 18.477 \\
\hline Informação & $\begin{array}{l}\text { g1, g2, g5, g8, g9, g13, } \\
\text { g14, g15, g16, g17, } \\
\text { g18, g19, g20, g26, } \\
\text { g31, g38, g39, g50, } \\
\text { g52, g56, g59, g62, } \\
\text { g64, g65, g69 }\end{array}$ & 25 grupos & 175.354 & 4.600 \\
\hline Política & $\begin{array}{l}\mathrm{g} 6, \mathrm{~g} 17, \mathrm{~g} 18, \mathrm{~g} 19, \mathrm{~g} 24, \\
\mathrm{~g} 28, \mathrm{~g} 30, \mathrm{~g} 36, \mathrm{~g} 48, \\
\mathrm{~g} 49, \mathrm{~g} 53\end{array}$ & 11 grupos & 192.786 & 7.980 \\
\hline Solidariedade & $\begin{array}{l}\mathrm{g} 3, \mathrm{~g} 4, \mathrm{~g} 10, \mathrm{~g} 11, \mathrm{~g} 12, \\
\mathrm{~g} 21, \mathrm{~g} 22, \mathrm{~g} 25, \mathrm{~g} 32, \\
\mathrm{~g} 33, \mathrm{~g} 34, \mathrm{~g} 35, \mathrm{~g} 43, \\
\mathrm{~g} 44, \mathrm{~g} 47, \mathrm{~g} 51, \mathrm{~g} 52, \\
\mathrm{~g} 56, \mathrm{~g} 57, \mathrm{~g} 58, \mathrm{~g} 69\end{array}$ & 21 grupos & 159.943 & 1.195 \\
\hline
\end{tabular}

De acordo com o Quadro 1, observa-se que dentre os assuntos categorizados os que mais apresentaram grupos a eles relacionados foram, em ordem decrescente: informação com 25 grupos, seguido por solidariedade com 21 grupos, educação com quinze grupos, política juntamente com humor com onze grupos cada um e, por fim espiritualidade com quatro grupos. 
Importante ressaltar que dezessete grupos devido suas características de descrição e teor de postagens apresentam-se em dois ou três assuntos simultaneamente, conforme pode ser verificado no Quadro 1. Nos assuntos espiritualidade e solidariedade (g10 e g57), educação e informação (g15, g20, g26, g62 e g64), informação e política (g17 e g18), educação e solidariedade (g21, g33, g34 e g58), informação e solidariedade (g52, g56 e g69) e o grupo g19 presente nos assuntos educação, informação e política simultaneamente.

Percebe-se um maior número agregado no total de membros nos grupos relacionados ao assunto humor com 1.385.992 membros, seguido por política, informação, solidariedade, educação e espiritualidade, respectivamente. Já em relação ao total de postagens ao dia por assunto, observa-se que o humor apresenta novamente um maior número com 18.477 postagens, seguido respectivamente por política, informação, educação, solidariedade e espiritualidade.

A seguir observa-se a Figura 1 representando o sociograma do modelo teórico conforme sistematização dos dados anteriormente categorizados.

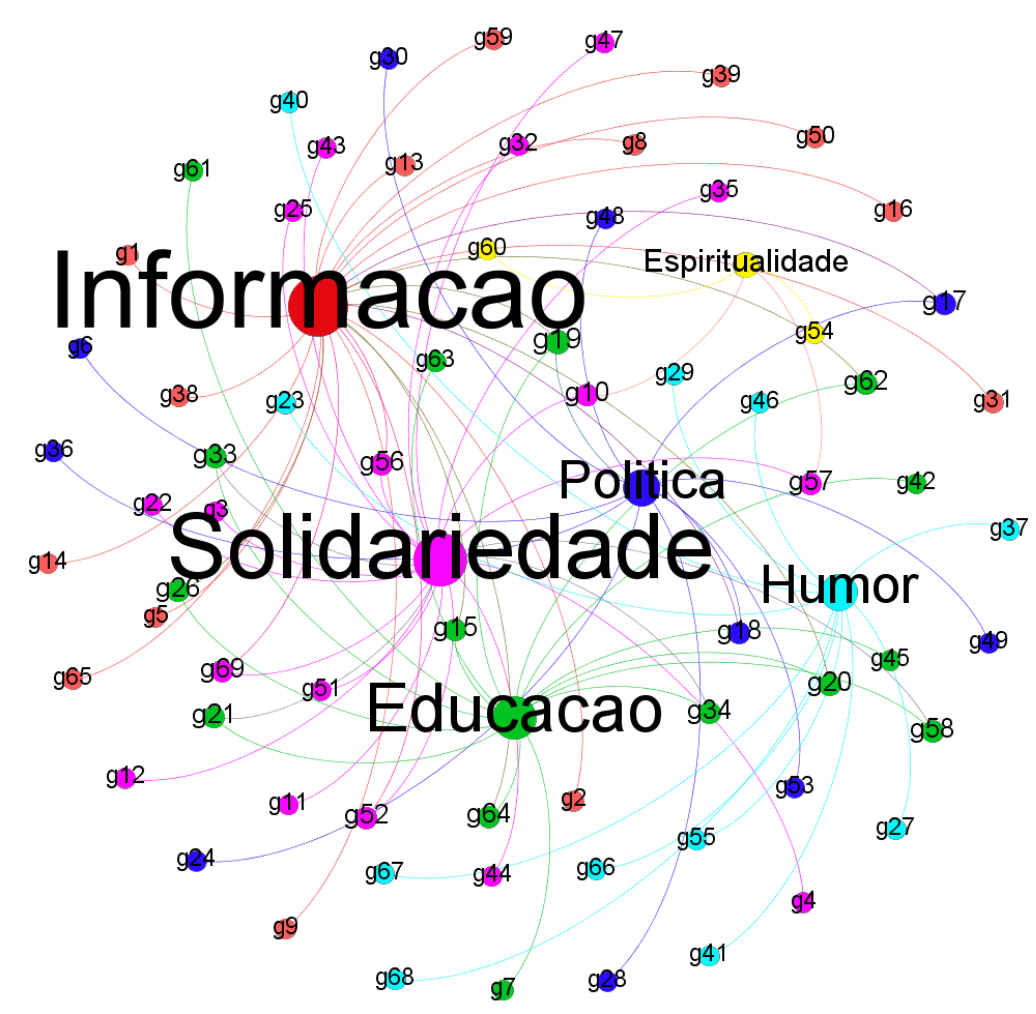

Figura 1 - Rede de relações entre os grupos do Facebook e assuntos associados ao coronavírus.

Na Figura 1 é possível verificar a representação do sociograma das relações entre os grupos (g1 ao g69) com os assuntos em destaque em torno do descritor coronavírus. Os assuntos informação e solidariedade apresentam-se em maior destaque ou peso na rede, pois seus nós recebem maiores números de ligações, ou arestas, por grupos, apresentando assim grande centralidade de grau (relacionado ao nó que está diretamente ligado a muitos outros, próximo a $100 \%$ ) na rede. Já os assuntos educação, política e humor seguem respectivamente com centralidade de grau significativa, porém inferior à informação e solidariedade e, a espiritualidade com a menor centralidade de grau na rede. 
Conforme ainda na Figura 1, todos os grupos possuem as respectivas cores de seus nós de origem representados pelos assuntos, sendo possível visualizar aqueles dezessete grupos que possuem centralidade de intermediação entre dois ou três assuntos. Esses grupos atuam como nós que podem controlar e ou mediar o fluxo de informações, ou seja são considerados importantes articuladores do fluxo da rede.

\section{Discussão}

A partir da inserção dos dados, no software Gephi para elaboração da rede, foi possível visualizá-la graficamente, correspondendo a imagem do sociograma à dinâmica dos grupos do Facebook em torno dos assuntos relacionados ao período da epidemia ocasionada pelo coronavírus no Brasil. À primeira vista, considerando todo o território nacional, os 69 grupos podem dar a impressão de pequena quantidade temática. Contudo, essa se refere a apenas um momento de 1 dia do ano, relativa a coleta de dados. Ou seja, considerando o breve momento da coleta de dados, representam uma importante materialização visual da rede pretendida, ensejando prospecções futuras e facultando o uso da ARS não só aplicada a processos avaliativos, de planejamento ou tomada de decisão, mas também na investigação de fenômenos emergentes das mídias sociais.

Considerando que as mídias sociais se caracterizam como uma nova forma de comunicação entre muitos usuários, elas apresentam-se, de fato, como uma rede, sendo seus nós os grupos do Facebook e os assuntos relacionados à pandemia com suas relações, a maneira como se dispõem na rede, a análise visual deste sistema permite avaliar possibilidades e demandas da população nesse período no Brasil.

Informação e solidariedade foram os assuntos que apresentaram grupos com maiores ligações, ou arestas, entre si, ambos com 25 e 21 grupos respectivamente. Dada a importância do momento no qual o Brasil e o mundo vivenciam, em que o excesso de informação sobre o número de infectados, recuperados e mortos pela doença se tornaram recorrentes na população. Por outro lado, se o confinamento atraiu os usuários para assuntos relacionados a informação e solidariedade, também tem sido um intensificador de conflitos familiares, pois de acordo com o Fórum Brasileiro de Segurança Pública, o índice de agressão a mulher subiu em $20 \%$ em março de 2020, em relação ao mesmo mês no ano anterior e, o Ministério Público apontou um acréscimo de $51 \%$ nas prisões em flagrante em decorrência de violência doméstica contra a mulher (30).

Corroborando com o fato de que o Facebook desempenha um papel importante no processo de informação, mesmo que seja necessário atenção e cuidado com informações distorcidas, em particular as relacionadas à saúde (31), verifica-se que o número de usuários dessa e de outras redes, expandiu-se exponencialmente em todo o mundo, tornando-se a principal fonte de informação, enquanto a confiança na mídia tradicional tem demonstrado diminuir ao longo dos anos (32). Neste contexto de confinamento a solidariedade como um nó de grande centralidade de grau, conforme sociograma da Figura 1, reforça de fato a grande mobilização de grupos, representados por 21 nós, que se comprometem a ajudar e auxiliar pessoas com itens de cestas básicas, de alimentação e de proteção pessoal, como máscaras ou álcool gel $70 \%$ a populações de grande vulnerabilidade. Tais medidas encontram-se de certa forma como mudanças de um comportamento antes conhecido como competitivo e individualista (33), para um comportamento aparentemente mais solidário e coletivista que nestes tempos de pandemia impõe a humanidade mudança radical na forma de viver e conviver socialmente (34).

Em um momento no qual o usuário é ao mesmo tempo assolado a todo instante por uma quantidade excessiva de conteúdo referente a medicamentos, tratamento e uma possível vacina para COVID-19, nem todo conteúdo pode ser considerado, haja vista as 
denominadas fake news, que distorcem a veracidade informacional (35). Ao mesmo tempo diversos grupos se organizam para trazer a educação com embasamento científico nesse contexto, aqui verificado, organizando-se em quinze grupos ao redor desse assunto, a maior parte com preocupações de compartilhar medidas de prevenção para os usuários com links de instituições de pesquisa de referência nacional e até internacional. A existência desses grupos com tais objetivos, cresce como um fenômeno de grande repercussão nas redes sociais digitais, sobretudo quando ocorrem acontecimentos de grande impacto para a sociedade, como na área de saúde, nesse momento de pandemia (36).

De acordo com o exposto, mesmo diante de um período de incertezas em face a COVID19 e suas consequências a saúde e demais áreas, percebem-se diversos movimentos de cunho político da população em reação às medidas econômicas e sociais dos governos federal, estaduais e municipais em todo o Brasil, desde então, sendo as mídias sociais o campo dessas manifestações, sejam elas contra ou favor dessas medidas. Pois as mídias sociais permitiram que a coletividade desenvolvesse novas estratégias de acesso, pressão e comunicação com os diferentes níveis de governo, criando um novo espaço público de debate (37).

De fato, tais estratégias são perceptíveis, como se pode observar na centralidade de grau em onze grupos, ou nós, estabelecendo ligações ao assunto política. Nestes destacam-se dentre as diversas manifestações que se configuram de maneiras distintas, as relacionadas ao auxílio financeiro emergencial do governo federal e o direito às liberdades individuais, pois alguns Estados da Federação têm adotado medidas distintas de menor flexibilização de atividades comerciais e de lazer que outros. Uma vez que tais preocupações se mostram evidentes atualmente, pois a pandemia ocasionada pelo coronavírus está paralisando, não só a vida dos indivíduos, mas também a economia mundial e os Estados poderão ter enorme dificuldade de se reerguerem futuramente (38).

Mesmo que a política seja um assunto que se distingue do humor em todos os aspectos, ambos, porém apresentaram mesma centralidade de grau. Verifica-se que essa equivalência de pesos destes dois interesses aparentemente antagônicos, indica que os usuários destas redes possivelmente identifiquem que ambas se imbricam na rede de relações de causa e efeito, inerentes a vida em sociedade, sendo impossível sua dissociação, mesmo que para tal, se utilizem do humor. A maioria desses grupos encontrados, compartilham seus conteúdos de humor sob a forma de memes que se caracterizam como algo que se difunde rapidamente na rede, tornando-se "viral", que podem ser uma foto, ideia, frase, expressão entre outras manifestações (39).

Por fim o assunto espiritualidade, apesar de ter apresentado o menor número de nós a ele relacionados, com 4 grupos, possui relevância nesse contexto. O termo Espiritualidade vai além da religiosidade expressada por cada indivíduo, envolvendo as crenças, as emoções, as práticas e os relacionamentos dos indivíduos em relação a um poder superior ou um ser divino, o sagrado (40), não se restringindo apenas às denominações religiosas pois estas estão associadas a um sistema organizado de crenças e práticas na qual o indivíduo se relaciona com o sagrado (41). E nesse momento ímpar de pandemia pela COVID-19, situação essa que pode ser geradora de sentimentos como insegurança, aflição e medo frente a possibilidade de contágio/infecção e de morte provocadas pelo coronavírus (42), certamente seja este um momento no qual as pessoas se conectem em torno da espiritualidade como alento aos seus anseios através de grupos nas mídias sociais.

Portanto diante da possiblidade de visualização da rede aqui exposta no momento atual em que o Brasil e o mundo atravessam, foi possível detectar, considerando as limitações da análise, a forma como uma parcela da população brasileira tem se conectado através 
da formação de grupos do Facebook nesse momento, em torno de assuntos pelos quais são relevantes (educação, espiritualidade, humor, informação, política e solidariedade). Essa capacidade de avaliação conseguida por meio da simples visualização geral do cenário atual virtual, viabilizada pela utilização da abordagem da ARS, mostra-se elemento de compreensão às necessidades da população a serem utilizadas como alicerces às políticas públicas em saúde.

\section{Conclusões}

Diante do exposto, foi possível constatar o grande potencial de utilização e aplicação da ARS na compreensão da formação de grupos do Facebook, em torno dos três assuntos que mais se evidenciaram (informação, solidariedade e educação), no momento de epidemia da COVID-19 no país causada pelo agente etiológico coronavírus, apesar das limitações relativas a natureza dos dados aqui empregados. Compreender as demandas dos usuários de uma mídia social como o Facebook com milhares de usuários no Brasil e entender suas manifestações, mesmo que com uma única métrica, a da centralidade, foi possível, mesmo assim, constatar o grande potencial de utilização da ARS como possível auxílio a políticas públicas em saúde. Tornando-se útil e cada vez mais imprescindível essa ferramenta como forma de comunicação entre população e autoridades públicas, uma vez que as mídias sociais já fazem parte do cotidiano de comunicação entre população e agências governamentais e seus representantes, num mundo conectado em redes.

\section{Referências}

1. Toledo Junior ACC. Pragas e epidemias: histórias de doenças infecciosas. Belo Horizonte: Folium, 2006.

2. Senhoras EM. Coronavírus e o papel das pandemias na história humana. Boletim de Conjuntura [Internet]. 2020 Jan 31; [citado 2020 Abr 13]; 1(1): 31-34. Disponível em: https://revista.ufrr.br/boca/article/view/Eloi

3. Martins MM, Junges F, Cantão PC, Brittes AHC, Machado JN. Epidemias Mundiais: um histórico sobre as principais doenças com potencial emergente. SIEPE [Internet]. 2016; UNIPAMPA. Bagé, Rio Grande do Sul: 2020.

4. Alfani G, Murphy TE. Plague and Lethal Epidemics in the Pre-Industrial World. The Journal of Economic History 2017; 77(1): 314-343.

5. Ministério da Saúde (BR), Secretaria de Vigilância em Saúde. Plano de Contingência Nacional para Infecção Humana pelo novo Coronavírus COVID-19. Brasília (DF): 2020.

6. Singhal T. A review of coronavirus disease-2019 (COVID-19). Indian J Pediatr 2020; 87(4): 281-286.

7. World Health Organization. Novel coronavirus (2019-nCoV): situation report - 22 [Internet]. Geneva: World Health Organization; 2020 [citado 2020 Mar 4]. Disponível em: https://www.who.int/docs/default-source/coronaviruse/situation-reports/20200211-sitrep-22ncov.pdf?sfvrsn=fb6d49b1_2.

8. Croda JHR, Garcia LP. Resposta imediata da vigilância em saúde à epidemia da COVID-19. Epidemiol Serv Saúde 2020; 29(1): e2020002.

9. Garcia LP, Duarte E. Intervenções não farmacológicas para o enfrentamento à epidemia da COVID-19 no Brasil. Epidemiol Serv Saúde 2020; 29(2): e2020222.

10. Ministério da Saúde (BR). Coronavírus Brasil. Painel COVID-19. [Internet]. Brasil [atualizado 2020 Jun 03; citado 2020 Jun 03]. Disponível em: https://covid.saude.gov.br/

11. Freitas ARR, Napimoga M, Donalisio MR. Análise da gravidade da pandemia de Covid-19. Epidemiol Serv Saúde 2020; 29(2): e2020119.

12. Horowitz J. Italy's health care system groans under coronavirus - a warning to the world. [Internet]. The New York Times 2020; 12 mar. Disponível em: 
https://www.nytimes.com/2020/03/12/world/europe/12italy-coronavirus-health-care.html

13. Carvalho MS, Lima LD, Coeli CM. Ciência em tempos de pandemia. Cad. Saúde Pública 2020; 36 (4): e00055520.

14. Modesto JA, Junior ME. Danos colaterais em tempos de pandemia: preocupações quanto ao uso dos dados pessoais no combate a COVID-19. Redes 2020; 8 (2): 1-19.

15. COVID-19 puts societies to the test. The Lancet Public Health [Internet]. 2020 Mai 01; [citado 2020 Mai 06]; 5 (5): 235-296. Disponível em: https://www.thelancet.com/journals/lanpub/article/PIIS24682667(20)30097-9/fulltext?dgcid=raven_jbs_etoc_email\#articleInformation

16. Devaux CA, Rolain JM, Colson P, Raoult D. New insights on the antiviral effects of chloroquine against coronavirus: what to expect for COVID-19? Int J Antimicrob Agents 2020; 55(5):105938.

17. Nielsen RK. The business of news. In: Witschge T, Anderson CW, Domingo D, Herminda A, editors. The Sage handbook of digital journalism. Los Angeles: Sage; 2016. p. 51-67.

18. Newman N, Fletcher R, Kalogeropoulos A, Levy DAL, Nielsen RK. Reuters Institute Digital News Report 2017. Reuters Institute Digital News Report 2017 [Internet]. Oxford: Reuters Institute, University of Oxford; 2017 [citado 2020 Mai 04]. Disponível em: https://bit.ly/2vl8USn.

19. Oh HJ, Ozkaya E, LaRose R. How does online social networking enhance life satisfaction? The relationships among online supportive interaction, affect, perceived social support, sense of community, and life satisfaction. Computers in Human Behavior 2014; 30:69-78.

20. Betsch C, Brewer NT, Brocard P, Davies P, Gaissmaier W, et al. Opportunities and challenges of Web 2.0 for vaccination decisions. Vaccine 2012; 30 (25): 3727-3733.

21. Grossetti M. Sociologie de l'imprevisible. Dynamiques de l'activitéetdes formes sociales. Paris: PUF Collection, 2004. 225p.

22. Grossetti M. Dynamiques des réseaux et des cercles. Encastrementset découplages. Revue d'économie industrielle 2003; 2: 327-55.

23. Tomael MI, Marteleto RM. Redes sociais de dois modos: aspectos conceituais. Transinformação 2013; 25(3): 245-53.

24. Varanda M. Acção colectiva entre pequenos empresários: uma análise de redes sociais. Análise Social 2007; 42(182): 207-30.

25. Rossi LP, Lovisi GM, Abelha L, Gomide M. Caminhos Virtuais e Autismo: acesso aos serviços de saúde em perspectiva da Análise de Redes Sociais. Ciênc. saúde coletiva 2018; 23 (10): 3319-3326.

26. Almeida CPB, Goulart BNG. Como minimizar vieses em revisões sistemáticas de estudos observacionais. Rev. CEFAC 2017; 19(4):551-555.

27. Coutinho T, Esher AF, Osorio-de-Castro CGS. Mapeando espaços virtuais de informação sobre TDA/H e usos do metilfenidato. Physis 2017; 27(3):749-769.

28. De-Paula FR, Mello MGS. Centro de Especialidade Odontológica e Unidade Básica de Saúde: análise de Redes Sociais como estratégia de governança. VITTALLE - Revista de Ciências da Saúde 2019; 31(2): 53-63.

29. Costa PHA, Ronzani TM, Colugnati FAB. Análise de Redes Sociais: Uma estratégia avaliativa para a rede de atenção aos usuários de álcool e outras drogas. Psicologia e Saúde Pública: Contribuições e Desafios. Juiz de Fora: UFJF; 2015. 227-246.

30. Em quarentena com o agressor. [Internet] Istoé online: Mariana Ferrari; 24/04/2020; [atualizado em 2020 Abr 30; citado em 2020 Mai 05]. Disponível em: https://istoe.com.br/em-quarentena-com-oagressor/

31. Camargo Jr. KR. Tentando dar sentido ao caos: ciência, política e a pandemia do COVID-19. Cad. Saúde Pública 2020; 36(4): e00088120.

32. Swift A. A confiança dos americanos na mídia de massa cai para um novo nível mais baixo. Gallup [Internet]. 2020; [citado 2020 abril 05]. Disponível em: https://news.gallup.com/poll/195542/americans-trust-mass-mediasinks-new-low.aspx

33. Rego S, Palácios M. Algumas lições que já devemos tentar aprender com a pandemia. Inf ENSP 2020; $1-2$.

34. Paraguassu EC. COVID-19 a relação direta entre o capital, solidariedade e as vidas. BJIHS 2020; 2(3):1-4. 
35. Albuquerque A, Quinan R. Crise epistemológica e teorias da conspiração: o discurso anti-ciência do canal "professor terra plana". Rev Mídia Cotid 2019; 13 (3): 83-104.

36. Oliveira TM, Martins RQR, Toth JP. Antivacina, fosfoetanolamina e Mineral Miracle Solution (MMS): mapeamento de fake sciences ligadas à saúde no Facebook. Reciis - Rev Eletron Comun Inf Inov Saúde 2020;14(1): 90-111.

37. Simonard P, Santos ARV. Identidade, pertencimento e engajamento político nas mídias sociais. R Inter Interdisc Interthesis 2017; 14(3): 16-31.

38. Maciei DN, Vosgerau BR, Andretta JT. O Papel do Estado pela atuação do poder judiciário nos conflitos contratuais em tempos de pandemia do COVID-19: A fraternidade como elemento de decidir. Rel Int Mundo Atual 2020; 1 (26):47-69.

39. Recuero, RC. Memes em weblogs: proposta de uma taxionomia. Rev Famecos 2007; 14(32): 23-31.

40. Curcio CSS, Moreira-Almeida A. Investigação dos conceitos de religiosidade e espiritualidade em amostra clínica e não clínica em contexto brasileiro: uma análise qualitativa. Inter Psicologia 2019; 32(2): 281-292.

41. Koenig HG, McCulloug M, Larson DB. Handbook of religion and health: a century of research reviewed. $1^{\mathrm{a}}$ ed. New York: Oxford University Press; 2001.

42. Tavares CQ. Dimensões do cuidado na perspectiva da espiritualidade durante a pandemia pelo novo coronavírus (COVID-19). J Health NPEPS 2020; 5(1):1-4. 